\title{
Strength and Stiffness of 3-Ply Industrial Bamboo Matting
}

\author{
Rubin Shmulsky, ${ }^{\mathrm{a}}$ Laurice Mara Spinelli Correa, ${ }^{\mathrm{b}}$ and Franklin Quin ${ }^{\mathrm{c}, *}$ \\ There is a pressing need to develop engineering standards for timber- and \\ other wood-based mats suitable for supporting construction vehicles, etc. \\ In 2018, a group of mat producers and users began discussing a potential \\ grading standard specific to mats. There are large gaps in the literature \\ regarding the performance of the available raw materials as well as bolt- \\ laminated mat systems. This study addresses the issue of determining the \\ strength and stiffness values of a commercially sourced industrial bamboo \\ mat. A total of seven $8 \mathrm{ft} \times 14 \mathrm{ft}(2.44 \mathrm{~m} \times 4.27 \mathrm{~m})$ commercial bamboo \\ mats were cut into 28 billets that were 21.5 in $(54.6 \mathrm{~cm})$ in width. The \\ bamboo mat billets were evaluated for bending stiffness (modulus of \\ elasticity [MOE]) and strength (modulus of rupture [MOR]) using a three- \\ point static bending test. The $5^{\text {th }}$ percentile non-parametric tolerance limit \\ $\left(5 \%\right.$ NTL) and design value for fiber stress in bending $\left(F_{b}\right)$ were calculated. \\ The mechanical property values measured for the 3-ply bamboo mat were \\ at least $25 \%$ less than values reported for mixed hardwood timber mats. \\ This type of structural performance information is helpful and useful in the \\ development of matting standards, as it describes the minimum \\ performance characteristics for this type of composite matting.
}

\begin{abstract}
Keywords: Crane; Construction mat; Timber mat; Industrial mat; Bamboo; Modulus of elasticity (MOE); Modulus of rupture (MOR); Strength; Stiffness

Contact information: a: Department of Sustainable Bioproducts, Mississippi State University, Box 9820, Mississippi State, MS 39762 USA; b: Department of Sustainable Bioproducts, Mississippi State University, Box 9820, Mississippi State, MS 39762 USA; c: Department of Sustainable Bioproducts, Mississippi State University, Box 9820, Mississippi State, MS 39762 USA; *Corresponding author: fq3@msstate.edu
\end{abstract}

\section{INTRODUCTION}

The development and use of industrial matting is well documented. Mats provide safe, stable, and flat work surfaces on which people, equipment, and machinery can operate during construction. In addition to providing site access for construction, they protect life, property, equipment, structures, and the environment. Mats are generally panelized. That is, their respective widths and lengths are many times greater than their thicknesses. Wood and timber are likely the most recognizable and routine materials that are used in this regard. The research related to the mechanical properties of industrial mats is gaining more attention. In particular, allowable design bending strength $\left(F_{\mathrm{b}}\right)$ based on modulus of rupture (MOR) as well as stiffness, reported as modulus of elasticity (MOE), are the two most routinely reported and used mechanical properties. Design strength allows a specifier to employ a mat under given loads and soil conditions in a safe manner with minimal risk of breakage or damage. The MOE relates to stiffness and can be used to calculate mat deflection under varying loading and soil conditions. This factor is critical with respect to overhead lifting and keeping machinery such as cranes from tipping. Ground disturbances, for example rutting, soil shear, and soil compaction are also influenced by mat stiffness. 
Thus, these mechanical properties influence safety, environmental protection, as well as utility value and overall costs.

Wood and timbers are likely the most recognizable materials that are used in mat construction. Past research has examined the mechanical performance of sawn hardwood timber mats (Owens et al. 2020). Yang et al. (2015) studied face-laminated pine lumber beams as a raw material that was intended for use in bolt-laminated mats. Prior to that study, Shmulsky and Shi (2008) investigated face-laminated low-grade hardwood lumber for use in bolt-laminated mats. Other works have investigated the composite effect of bolt laminated billets used in mats (Shmulsky et al. 2008) and the use of instrumentation to characterize stresses and deflection in mats during testing (Stroble et al. 2012). Additional timber and mat research and information can be found in Herberg (2018), NeLMA (2017), and the National Design Specifications for wood (NDS 2018). Additional work has been reported by Xiao et al. (2021) and Li et al. (2021) on the performance of bamboo crosslaminated timber. Both of these two investigations deal with adhesive bonded bamboo. None of these, however, mention or deal with mechanical properties of bolt laminated bamboo mats. Novel materials and mat architectures are continually being developed for commercial applications. Alternatives, such as composites (including bamboo), other biobased materials, polymers, and metals, are continually coming to market.

\section{EXPERIMENTAL}

\section{Materials}

In this research, commercially sourced 3-ply bolt-laminated bamboo mats were evaluated. The bamboo mats were acquired through a national industrial supplier in the USA. These are available throughout North America. The raw material bamboo was grown in Asia, and the mats were manufactured in Asia prior to being imported into North America. As sourced, the mats are available in $8 \mathrm{ft} \times 14 \mathrm{ft}(2.44 \mathrm{~m} \times 4.27 \mathrm{~m})$ sizes. For testing, billets of size approximately 21.5 in $(54.6 \mathrm{~cm})$ wide were ripped from these mats (Fig. 1). Four billets were produced from each parent mat. Each 3-ply mat was approximately 2.63 in $(6.68 \mathrm{~cm})$ thick, while each single layer was approximately 0.875 in $(2.22 \mathrm{~cm})$ thick. Individual layers were made of crushed bamboo that had been processed into adhesively bonded panels, somewhat analogous to plywood or oriented strandboard panels. The crushed bamboo used as raw material is often referred to as scrim. The panels were manufactured with waterproof structural adhesive for intended use in industrial, outdoor, and matting applications. With respect to mat architecture, the bottom (tension) face panel consisted of bamboo fibers all oriented parallel with the long axis of the mat. The middle lamina panels consisted of the bamboo fibers running perpendicular to the long axis of the mat. The top face (compression) panels consisted of three-layer architecture (most similar to plywood). In those top layers, the outer layer (faces) of bamboo fiber was oriented parallel with the long axis of the mat while the bamboo fibers in the middle layer of that panel were oriented perpendicular to the long axis of the mat. A schematic of this mat architecture is shown in Fig. 2. While this mat architecture is not symmetric through the thickness, it provides a relatively balanced overall panel construction and likely develops better wear characteristics on the surface ply as compared to a uni-directionally laminated facial panel. 


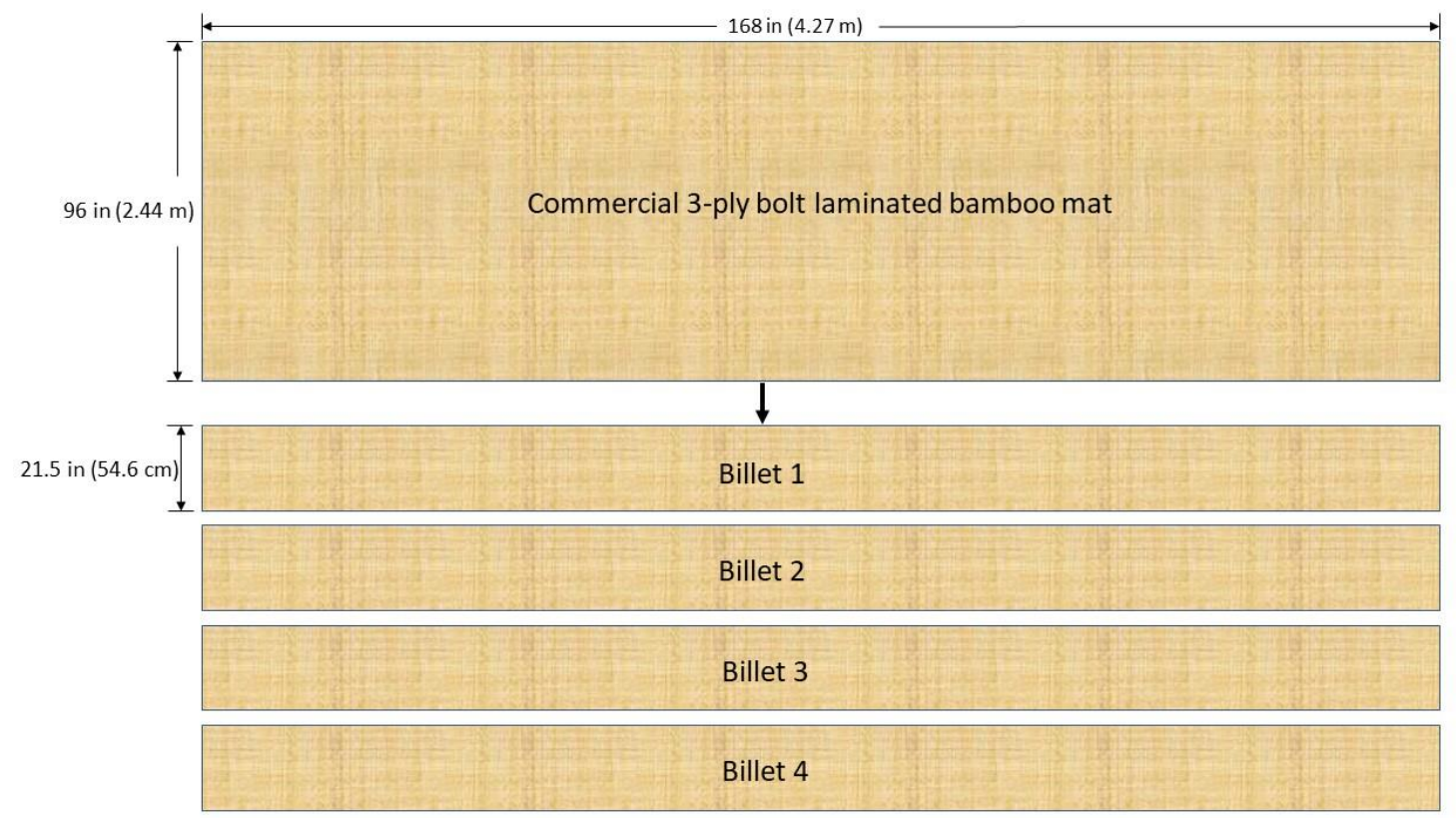

Fig. 1. Four testing billets were cut from each 3-ply bolt laminated bamboo mat

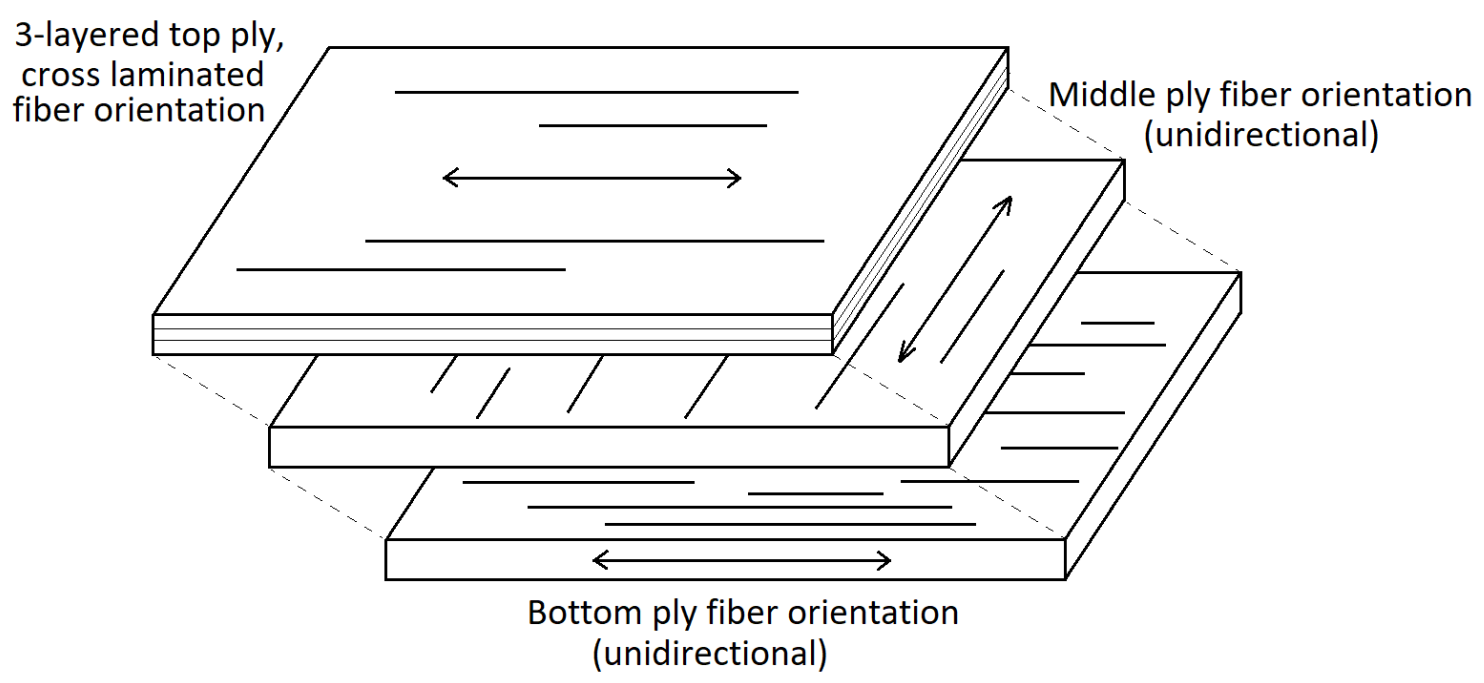

Fig. 2. Schematic of 3-ply bolt laminated mat illustrating the fiber orientation in the bottom, middle, and top plies

Commercial bolts of 3/8-in $(0.95 \mathrm{~cm})$ diameter were used to fasten the plies together (bolt laminated). The bolts were installed at an approximate schedule of 1.28 bolts per square foot $\left(13.8 \mathrm{bolts} / \mathrm{m}^{2}\right)$ of mat surface area. On the top surface, the bolt heads were set directly into the mat surface. On the bottom surface was a force distributing washer, approximately 2.5 in $(6.35 \mathrm{~cm})$ in diameter, was also installed between the nut and the bamboo surface.

\section{Methods}

To develop a non-parametric design for bending strength value, 28 billets were tested. The billets were tested in third point bending following ASTM 5456-17 (2017) with 
a modified span:depth ratio. The span to depth ratio was extended, as per the guidance of APA PRG 320 (2018) to encourage bending failure and discourage rolling shear failure in the composite section for this cross-laminated composite. A 28:1 span to depth ratio was used for testing. As such, the clear span was $73.5 \mathrm{in}(187 \mathrm{~cm})$ and the load heads were 24.5 in $(62.2 \mathrm{~cm})$ apart (Fig. 3). The billets were supported fully across their widths and the loads were applied across the full billet widths. The ends of the mats contained varying tongues and grooves/notches to facilitate interlocking among mats. In many cases, these tongues and grooves/notches were machined off the specimens during preparation. In cases where their remnants remained, any remnant tongues and grooves/notches were not included in the test span. In this manner, they did not influence the strength or more importantly the deflection and resultant stiffness. A partial stack of machined billets staged for testing is shown in Fig. 4. An exemplar photograph of a single billet in the universal test machine frame is shown in Fig. 5.

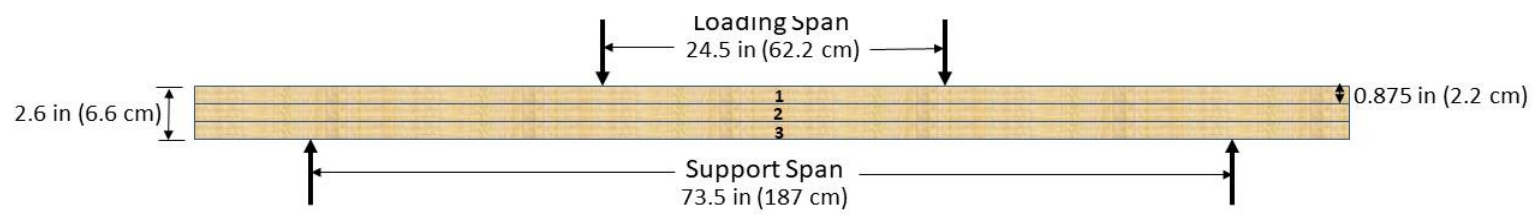

Fig. 3. Third point loading configuration for 3-ply bolt laminated bamboo mat

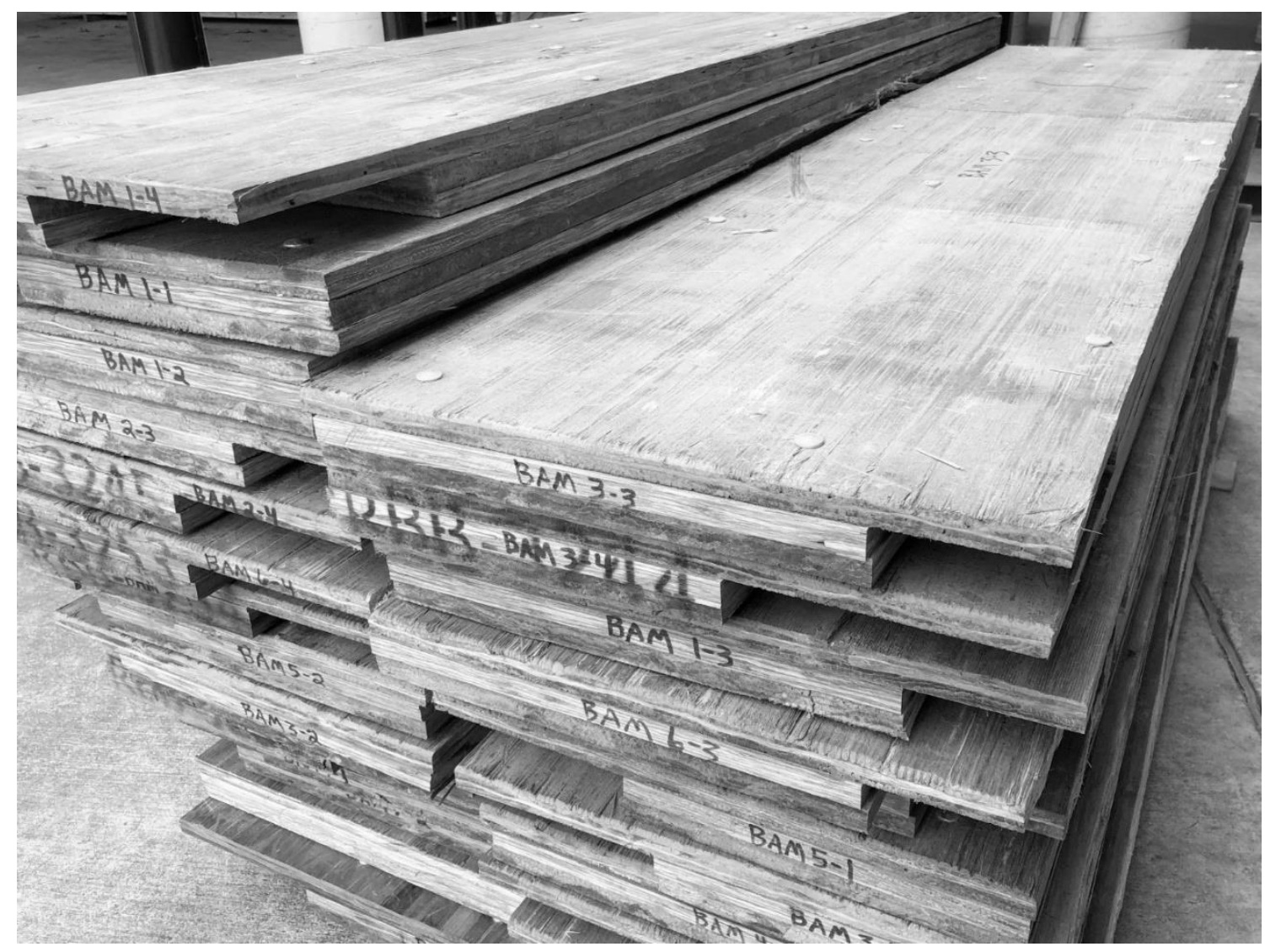

Fig. 4. Stack of machined 3-ply bamboo billets staged for mechanical testing 


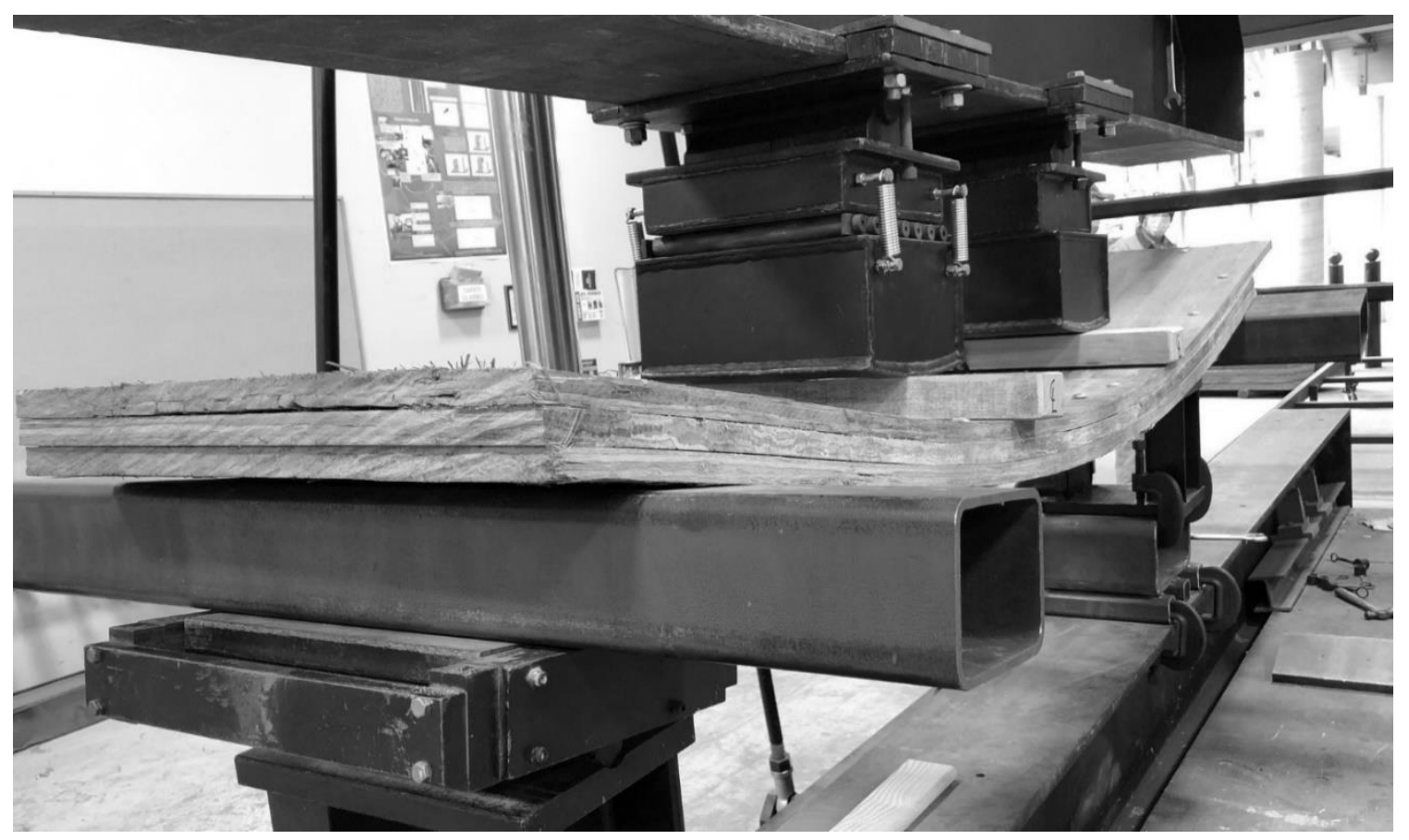

Fig. 5. Exemplar picture of one billet during destructive flexural testing

With respect to section properties, the gross thickness (2.625 in) was used in calculation of section modulus and moment of inertia. When it comes to bending strength analysis, the order statistic for the 5\% tolerance limit was determined per ASTM D291517 (2017). As such, the non-parametric $5^{\text {th }}$ percentile is taken as the lowest observation among a minimum of $28 \mathrm{ranked} /$ sorted observations. Further, the allowable design value for fiber stress in bending $\left(F_{b}\right)$ was calculated by dividing the non-parametric $5^{\text {th }}$ percentile by a combined load duration and safety factor of 2.1, following ASTM 5456-17 (2017). The load duration component of this factor is based on 10 years (cumulative) at full design load. The $F_{\mathrm{b}}$ calculation did not consider any adjustments to uniform loading conditions. Given that an industrial mat routinely only lasts 3 to 5 years, this number is thus considered as conservative. With respect to stiffness, the numerical average MOE is reported for design.

\section{RESULTS AND DISCUSSION}

The performance of the tested 3-ply bamboo mats is shown in Table 1 . The design value for $F_{\mathrm{b}}$ was $1,174 \mathrm{psi}(8,090 \mathrm{kPa})$, and the average MOE was 279,000 psi (1,920 MPa). An exemplar load-deflection curve from one specimen is shown in Fig. 6. This study presents a portion of ongoing testing and assessment in support of the industrial mat sector. The bolt lamination schema associated with these mats did not facilitate the development of full composite action among the plies. Therefore, bolts placement did not prevent layers from acting independently. As a result, shear between layers was greater than expected generating non-recoverable fiber crushing around bolt areas and panel's delamination (Fig. 7). While this bolt lamination scheme may facilitate rapid production, sufficient strength, and stiffness for shipping and handling in service, it does not appear to capitalize on the full potential mechanical value, particularly with respect to MOE, of the constituent plies. 
For comparison, the allowable design strength $\left(F_{\mathrm{b}}\right)$ of these 3 -ply bamboo mats $(8,090 \mathrm{kPa})$ is approximately half of that for mixed hardwood timber mats $(15,990 \mathrm{kPa})$ as reported by Owens et al. (2020). By similar comparison, the stiffness (MOE) of these 3-ply bamboo mats $(1,920 \mathrm{MPa})$ is approximately one quarter of that for mixed hardwood timber mats (7,650 MPa) as reported (Owens et al. 2020). The stiffness would increase with minimal additional cost if the discrete bamboo lamina could be more securely fastened to each other and thereby develop better composite action.

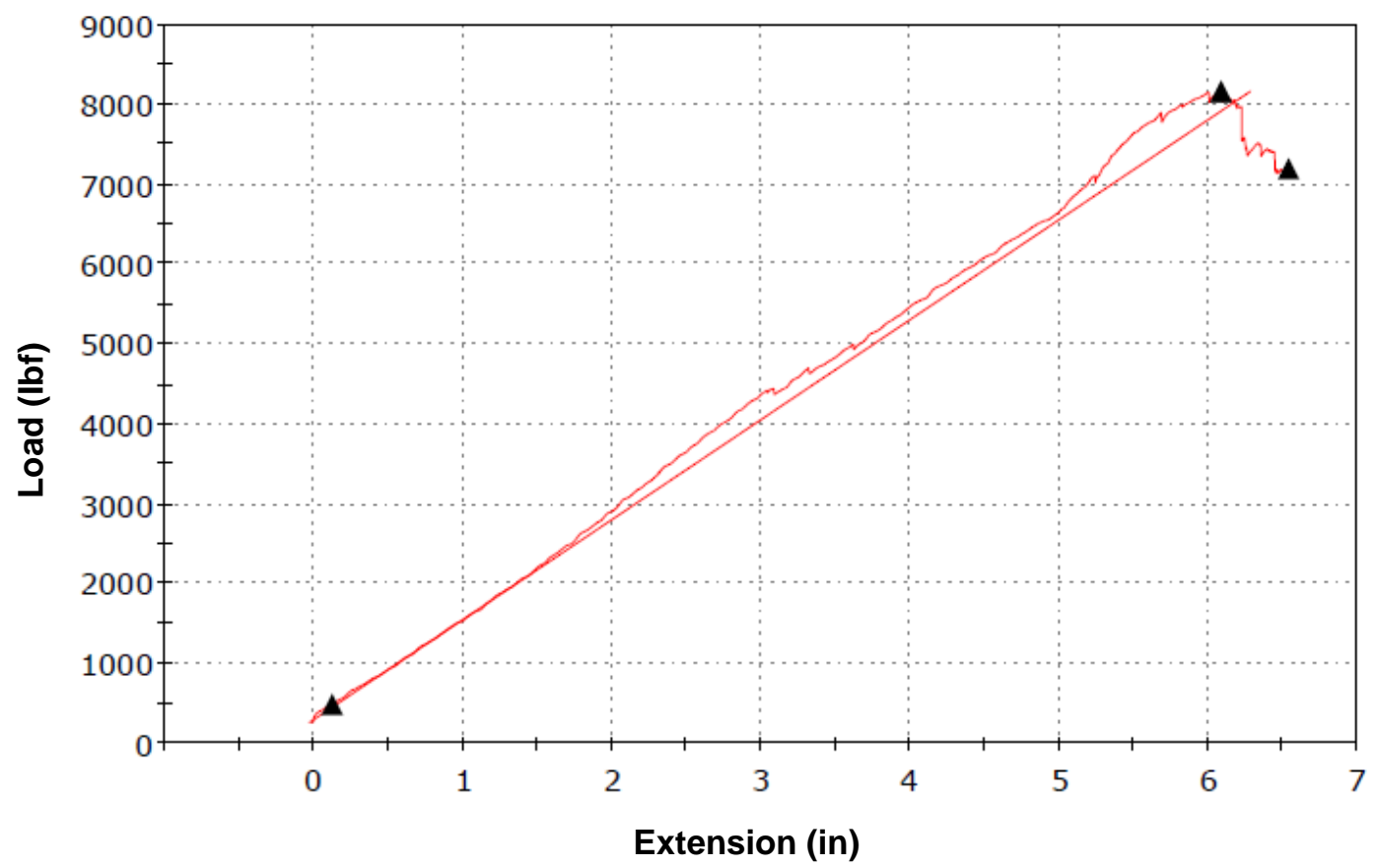

Fig. 6. Exemplar chart of the load deflection curve of a single specimen

Table 1. Mechanical Strength and Stiffness Summary Statistics for 3-Ply Bamboo Mats

\begin{tabular}{|c|c|c|}
\hline & Strength (MOR) & Stiffness (MOE) \\
\hline Number & 28 & 28 \\
\hline Average & $3,749 \mathrm{psi}$ & $279,000 \mathrm{psi}$ \\
& $(25,800 \mathrm{kPa})$ & $(1,920 \mathrm{MPa})$ \\
\hline Maximum & $5,310 \mathrm{psi}$ & $320,000 \mathrm{psi}$ \\
& $(36,600 \mathrm{kPa})$ & $(2,210 \mathrm{MPa})$ \\
\hline Minimum & $2,465 \mathrm{psi}$ & $240,000 \mathrm{psi}$ \\
& $(17,000 \mathrm{kPa})$ & $(1,650 \mathrm{MPa})$ \\
\hline Coefficient of Variation & $15.7 \%$ & $6.9 \%$ \\
\hline Confidence) & $2,465 \mathrm{psi}$ & Not applicable \\
\hline \multirow{2}{*}{$F_{\mathrm{b}}$} & $(17,000 \mathrm{kPa})$ & Nolerance Limit $95 \%$ applicable \\
\hline
\end{tabular}




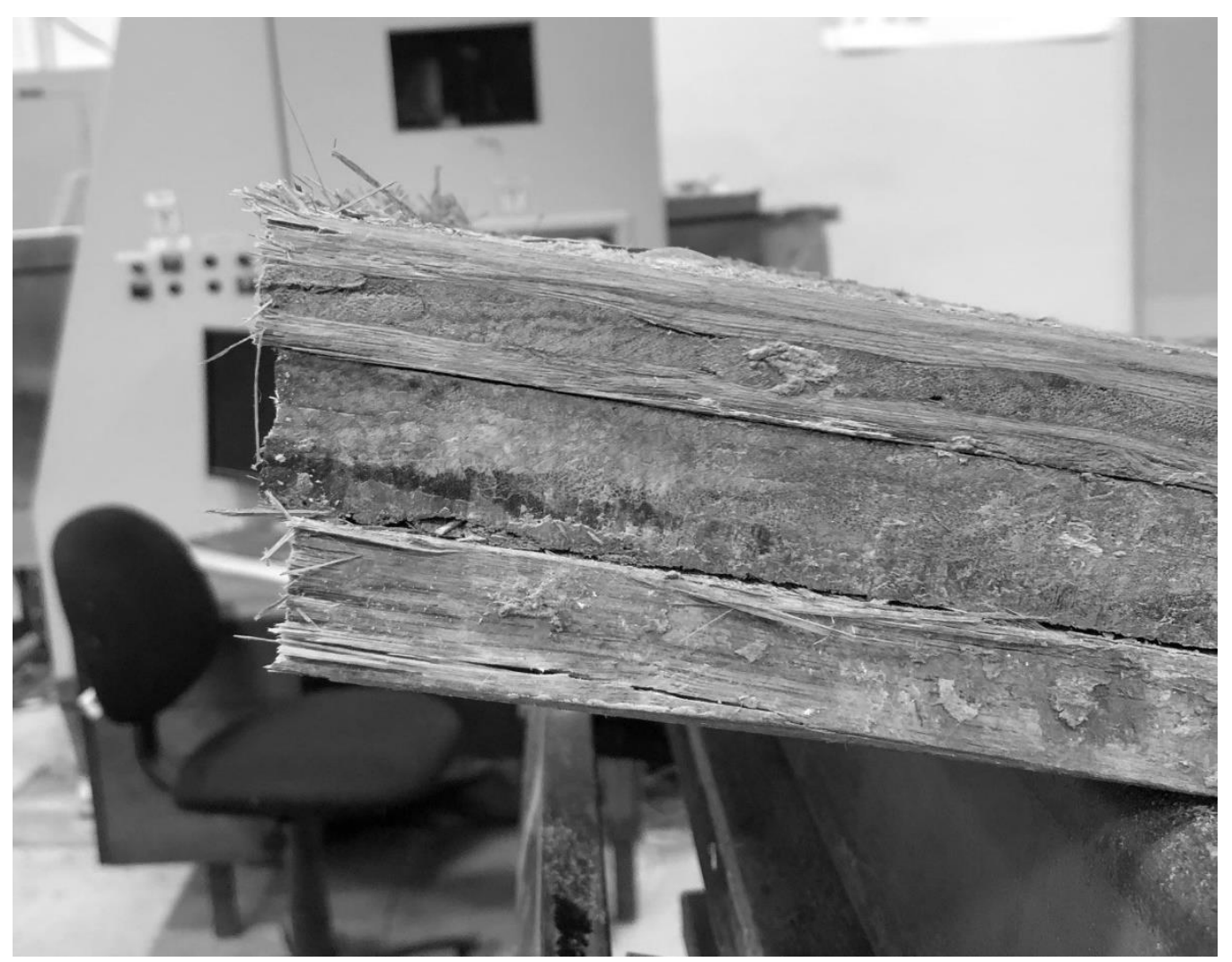

Fig. 7. The end of an exemplar billet during mechanical testing; the sliding action of the three individual plies under flexural strain is visible

\section{CONCLUSIONS}

1. Allowable design values for flexural strength and stiffness for a commercially available bamboo mat were developed.

2. The bamboo mats performed with a relatively small coefficient of variation, particularly with respect to stiffness. This high degree of uniformity is helpful and favorable when considering structural applications.

3. The strength and stiffness values for the bamboo mats were approximately $50 \%$ and $25 \%$ less, respectively, compared to mixed hardwood mats.

4. The stiffness of the bamboo mats could be increased at a minimal cost if the bamboo layers could be more securely fastened together to behave as a single layer. Better composite action could be developed between the 3-bamboo layers, such that they acted as a single member rather than as three separate layers, much greater stiffness would be developed at that time.

5. Quantitative mechanical property information (e.g. MOR, Fb, and MOE) from commercially available matting materials such as this is highly valuable toward the development of matting performance standards. 


\section{ACKNOWLEDGMENTS}

This publication is a contribution of the Forest and Wildlife Research Center at Mississippi State University. This study is supported by the National Institute of Food and Agriculture, U.S. Department of Agriculture, and McIntire-Stennis Project under accession number MISZ-065940.

\section{REFERENCES CITED}

APA PRG 320 (2018). "Standard for performance-rated cross-laminated timber," The Engineered Wood Association, Tacoma, WA, USA.

ASTM D2915-17 (2017). "Standard practice for sampling and data-analysis for structural wood and wood-based products," ASTM International, West Conshohocken, PA, USA.

ASTM D5456-17 (2017). "Standard specification for evaluation of structural composite lumber products," ASTM International, West Conshohocken, PA, USA.

Herberg, E. (2018). Flexural Performance of Nail-Laminated Timber Crane Mats, Master's Thesis, University of Minnesota, University Digital Conservancy, Minneapolis, MN, USA.

Li, H., Wang, B. J., Want, L., Wei, P., Wei, Y., and Wang, P. (2021). “Characterizing engineering performance of bamboo-wood composite cross laminated timber made from bamboo mat-curtain panel and hem-fir lumber," Composite Structures 266, article no. $113785,13 \mathrm{pp}$.

NDS. (2018). "National design specification for wood construction," American Wood Council. Washington, DC.

NELMA. (2017). "Standard grading rules for Northeastern lumber," Northeastern Lumber Manufacturers Association. Cumberland, ME.

Owens, F. C., Seale, R. D., and Shmulsky, R. (2020). "Strength and stiffness of 8-inch deep mixed hardwood composite timber mats," BioResources 15(2), 2495-2500. DOI: 10.15376/biores. 15.2.2495-2500

Shmulsky, R., Saucier, C. L., and Howard, I. L. (2008). "Composite effect of boltlaminated sweetgum and mixed hardwood billets," Journal of Bridge Engineering 13(5), 547-549. DOI: 10.1061/(ASCE)1084-0702(2008)13:5(547)

Shmulsky, R., and Shi, S. (2008). "Development of novel industrial laminated planks from sweetgum lumber," Journal of Bridge Engineering 13(1), 64-66. DOI: 10.1061/(ASCE)1084-0702(2008)13:1(64)

Stroble, M. F., Howard, I. L., and Shmulsky, R. (2012). "Wood construction platform design using instrumentation," Wood Material Science and Engineering 7(1), 13-24. DOI: 10.1080/17480272.2011.637132.

Xiao, Y., Cai, H., and Dong, S. Y. (2021). "A pilot study on cross-laminated bamboo and timber beams," Journal Structural Engineering. (ASCE). 147(4), article no. 06021002, 7 pp. 
Yang, B. Y., Shmulsky, R., and Seale, R. D. (2015). "Development of laminated planks from southern pine lumber," European Journal of Wood and Wood Products 73, 547549. DOI: 10.1007/s00107-015-0915-z

Article submitted: June 8, 2021; Peer review completed: July 17, 2021; Revisions accepted: July 29, 2021; Published: August 1, 2021.

DOI: 10.15376/biores.16.3.6392-6400 